\title{
Already Connected Digital Early Childhood between Digital Media and the Net
}

\author{
Maria Grazia Simone ${ }^{1, *}$ \\ ${ }^{1}$ Faculty of Psychology, eCampus On Line University, Via Isimbardi, 10, 22060 Novedrate \\ $\mathrm{CO}$, Italy \\ *Corresponding author: Faculty of Psychology, eCampus On Line University, Via Isimbardi, \\ 10, 22060 Novedrate CO, Italy. E-mail: mariagrazia.simone@uniecampus.it
}

Received: May 13, 2020 Accepted: July 21, 2020 Published: August 7, 2020

doi:10.5296/ije.v12i3.17504 URL: https://doi.org/10.5296/ije.v12i3.17504

\begin{abstract}
Children under seven spend most of their free time using digital technology. Educational contexts, such as school and family, would sometimes seem disinterested in the actual understanding and management of the phenomenon. They are unprepared to provide effective educational indications in this regard. Pedagogical reflection also appaears to be late about the relationship between digital media and early childhood. The paper tries to fill this research gap by trying to answer these questions: How to interpret the wide diffusion of digital media and the net among very young children? What does the screen convey to them? What development gains and educational needs can be covered instead? Under what conditions is the virtual an educational environment?
\end{abstract}

Keywords: digital media, Internet, children, gaming, learning, virtuality 


\section{Grown on "Milk and Technology"}

Interest in digital media and internet is growing for children under the age of seven.

Nonetheless, socio-educational policies ignore this specific age group. The attention is almost exclusively on the older ones (Stella \& Riva et al., 2014), in particular on teenagers. Perhaps we do not want to recognize an active role in the use of digital media and the net in early childhood.

Gaps and absences in knowledge still exist, and it will be important for scholars over the coming years to continue research into young children's digital literacy practices, both in homes and communities and across early years' settings (Scott \& Mash, 2018).

The research questions are the following: How to interpret the widespread diffusion of digital media connected to the network among young children? What does it mean to spend your free time in front of the digital screen? What are the educational earnings? what are the disadvantages instead? under what conditions is the virtual an educational environment?

Recent surveys indicate that internet access by children under the age of seven continues to grow and that they access it at an ever lower age (Suoninen, 2013).

The little ones are active users of digital technologies. They have the ability to connect to the internet through a variety of devices (ipod, tablet, smartphone, computer, touchscreen device, etc.) which represent, for children, important access keys to the virtual world.

Touchscreen technologies are functional for children who experience the sensorimotor phase because it is possible, for them, to easily press the buttons and icons with minimal help from adults, obtaining a greater level of independence, exploration and standalone game. Notebooks or personal computers usually require support from adults.

However, it is very important to remind that, in the sensorimotor phase and then also in the pre-operational one, a crucial role for child development is played by fine motor skills: performing refined, repeated and precise gestures (handling various types of material, tracing the outlines of a drawing, fastening and unfastening, threading, etc.) which involve eye-manual coordination.

These important skills go beyond simply tinkering on a keyboard or tablet, and cannot be reduced to pressing buttons as they require, among other things, constant interaction with others and with the external environment.

Very young children grow up at ease with digital devices, effective cultural and socializing tools in every living space and for every age group.

Nowadays we can find a very huge scientific literature on the presence and use of educational technologies in schools, but it is different for the domestic consumption of the internet by very young children who have had, so far, little attention as an effective research topic. Consequently, the methodological indications on what children can explore and learn through online gaming are scarce and, at times, contradictory. 
Investigating the media use of children, who sometimes still do not speak and who are often not yet included in educational services, raises various methodological and scientific problems (Livingstone, Haddon 2008), as well as ethics.

\section{On Line Childhood Activities}

Children, in the early childhood phase, would seem to look at the internet as an interesting and stimulating play environment. They prefer trendy online games, often advertised by the media while, upon reaching school age, their preferences change from play to information, to school research and socialization (Childwise, 2012).

Grown on "milk and technology" from birth, the little ones incorporate digital devices into their gaming activities without differentiation. They move easily, for example, from an exercise game into reality to an online game session, playing an avatar, their favorite superheroes, etc. Adults, with a nostalgic attitude, often judge the value and meaning of the digital game expressed by the little ones. They look at digital game with suspicion and evoke an idealized representation of the childhood game, referable to their memories of children lived in the absence of digital technologies.

In addition to the fun that many children try to play, to watch video clips, to exchange messages or multimedia content with friends or family, their digital diet would lead them to develop some skills, such as reading supported by digitalization in fact predisposing them to a good future school achievement (Cavanaugh \& Gillan, 2004).

Many children reach school age with significant experience in the use of computers and internet. They show skills in browsing, retrieving and creating content. Having access to the internet has been positively related to verbal skills. An exception to this positive relationship is represented by the use of game consoles and equivalents that seem associated with inferior linguistic skills (Bittman, L., \& Rutherford et al., 2011). If used in a solitary and repeated way, these tools could generate a dimension of alianation from reality and predisposition to social isolation.

Social network sites aimed at teenagers and adults are visited by very young children.

Video viewing is one of the first activities carried out by young children on the Internet. Sites like YouTube offer a wide range of entertainment videos specially prepared for them, even in the $0-5$ age range (Burroughs, 2017).

Thanks to the easy-to-use graphical interface, even children aged between 2 and 3 can happen on this and similar web platforms, encountering videos that are not always suitable for their age in playlists. We can state that the access, apparently secure and advantageous, is not, not only from the point of view of privacy and security but also from the educational one: young users are often only "three clicks away" from the content suitable for a more mature audience (Buzzi, 2012). 


\section{The Child in the Virtual World}

From an educational point of view, through the use of the online game it is possible for the children to experiment, try new roles, "wear" identity, manage relationship with the rules, test themselves. In fact, even for the little ones, as well as for adults, digital media are suitable tools to encourage the expression of personal identity.

Digital devices offer highly interactive game modes. This aspect represents one of the strongest attraction factors, especially for the little ones, towards video games. They allow the baby-player to interact directly with the contents, to the point that the fate of the game depends on his skill to solve complex situations to achieve a stated goal. As in a fairy tale, even in the digital game the children tends to identify with the protagonist who, through progressive levels of difficulty, must reach the end having achieved a certain score, or having managed to solve a problematic situation. The interactive dynamic is enthralling and almost enveloping: it responds and adapts promptly to the choices and decisions of the little one. It makes him feel the only protagonist of the game, with specific aims to be achieved, tasks to be carried out, rules to be respected. The virtual interactive environment also contains, inside, a series of information that he is called to manage and process. From an educational point of view, the playful situation can be exploited to achieve advantages in terms of acquiring knowledge and reorganizing the I-World relationship.

The motivation that stimulates the child to act is also provided by the symbolic dimension. The "pretend of", the ability to alternate the plane of reality and that of fiction, increases the field of action of the little player, feeding his curiosity. Each type of game, not only the digital one, allows you to get out of reality, but also to penetrate it, to understand it, to enrich it with meanings. It has at the same time expressive function of the Self and of adaptation to the social reality; this double value is pedagogically relevant and must be carefully cultivated in children's education.

When we talk about virtuality, we mean the world of the possible (Paparella, 2000), a range of opportunities, an area of advantage and enrichment for the person. Already as children and then as adults, we must be able to distinguish between the contexts of reality and those of fiction. The virtual environment is a set of experiences for the children, who must be able to use it appropriately. When, in some way, the virtual is confused with the real, and today it happens more dramatically in the adolescence than in the childhood. This is an educational problem and an emerging pedagogical research track.

The virtual is the field of the possible, where you can find some learning opportunities, also useful from the didactic point of view: there is a setting for symbolic elaboration, for the management of the metaphor, for the effective use of the allusion, for the formulation of the hypotheses. The small child is able to pass easily from reality to unreality and in this pendular movement between the two floors he expresses his game and his identity. In this way, learning is easier. Symbolic processing, very rich in the field of the possible and therefore in the field of the virtual, becomes an extremely useful thing for learning, and therefore must be carefully promoted. Furthermore, the formulation of a hypothesis is an opportunity to exercise individual and group creativity. 
In the virtual space the person play the possibility, the motivation to dominate and possess the real. On the basis of all these considerations, it is evident that the virtual space is not to be demonized a priori, but to be used and managed, in an educational key, for the benefit of the person.

This is an exquisitely educational task regardless the impact with digital media; it is necessary to recognize that pedagogy focuses on the problem and reporting its urgency (Paparella, 2012).

\section{Feature Pedagogical Research Agenda}

The daily, assiduous use of the net by preschoolers represents a new phenomenon, only partially investigated by experts. Educators and parents are invited to reflect on ways to support the little ones while using these devices in an advantageous way. An analysis of parenting attitudes is also appropriate.

There should be a re-conceptualization of young children's learning in early years pedagogy and early childhood settings, as children under five are engaging with digital technologies in playing and learning at home. This cannot be overlooked by first education. Secondly, it is suggested that in today's world of digital technologies early childhood educators should re-examine the way children learn and the way in which their workforce organize learning environments (Palaiologou, 2014).

The observed increase in Internet use by children under the age of seven suggests that many parents are in favor of their children's early exposure to the web. Educators, both in the family and at school, would thus seem to understand the importance of digital technologies as learning tools which, if used judiciously, promote the linguistic, cognitive and social development of young children (Gimbert \& Cristol, 2004). At the same, is widely recognized that children have a transfer deficit, i.e. constantly poorer learning via television and touchscreens than face-to-face interaction (Hipp et al., 2017).

The problem is also that children in early childhood do not yet have independent judgment and show little ability to deal with internet-related risks compared to older children.

Consequently, it is always recommended that educators, at school or in the family, are constantly present when the child surfs and does not see a second cheap "babysitter" on the net after television.

It is also necessary to consider the imitation component of adult behavior that children use to approach reality. There is an inevitable modeling action for adult behavior also with respect to the use of the network and multimedia devices. It has been statistically shown that the parents' media habits significantly influence their children's exposure to the media and their opinion on what is the appropriate daily limit for them (Rek \& Kovacic, 2019).

The increasing percentage of young children that populates virtual worlds requires a more effective understanding of the ways in which social network sites mediate the socialization of 
children. Systematic attention is required in the physical places and on the specific practices in which children decide to engage (Grimes \& Fiels, 2012) and a reflection on the skills necessary for preschoolers to interact in the virtual world.

The educational intervention, in this area, must become prevention: the child is a subject not yet able to understand all the potential, but also the pitfalls, offered by the internet.

It would be too easy to blame digital technologies for having inhibited the possibility for children to play in the traditional way. In fact, many social, cultural and economic changes have occurred and have progressively changed the way and the time playing in the new generations. It is undeniable that, following industrialization, urbanization and the need to supervise, the possibilities for children to play outdoors have significantly reduced while spontaneous play has considerably lost altitude, increasingly being replaced by recreational activities organized and supervised by adults in special equipped spaces.

It is a duty of the adults, and not the child, to take care of the risk and the safety when children stay online. The socio-emotional well-being of an increasingly affectionate user of digital devices must be guaranteed. It should also be considered that, at any age, digital technology performs specific functions (entertainment, information, socialization... and much more) for children and young people (Tisseron, 2016).

In the future pedagogical research agenda, few years ago, the keywords appear to be "protect" and "empower" (Holloway, Green, \& Livingstone, 2013) to ensure the socio-emotional well-being of the very young people.

Now, in addition to the strategies of active, restrictive, and co-viewing as parental mediation strategies, future research needs to consider the emergent strategy of participatory learning that involves parents and children interacting together with and through digital media (Schofield Clark, 2011) and the role of intentional media use (Hiniker \& Lee, 2017).

It is necessary to create, around the developing subject, an educational context that accompanies it, without alarmism and prejudices, but in a network logic between the various training agencies, along the paths of media use (Simone, 2008). In this way, a single educational ground is created characterized by open cooperation between the different educational agencies to deal in synergy with important issues and common problems of the education of the new generations to digital.

A contextual orientation towards the problem of digital play in the early years might better support also the teachers in preschool to effectively engage children in the range of critical thinking skills that are associated with the 'new learning' and "new literacies" movements in both primary and secondary education (Edwards, 2013).

It is an educational task to design common methodological lines for media education, shared among school educators, family members and those working in their spare time. Thus, advantageous opportunities for fruition and learning can be generated through digital media to guarantee to the new generations the opportunity to develop their digital literacy skills, ability to build interpersonal relationships, promotion of creativity, development of social 
skills also in the digital world.

Academics and educators need to examine their affordances more closely in order to identify what children gain from their playful engagement in these worlds and how their experiences can be built upon in early years settings and schools (Marsh, 2010).

In this way, the little ones are not only the youngest users of the new digital technologies but also the actual protagonists, future active citizens who are responsible for their online lives.

\section{References}

Bittman, M., Rutherford, L., Brown, J., \& Unsworth, L (2011). Digital Natives? New and Old Media and Children's Outcomes. Australian Journal of Education, 55(2), 161-175. https://doi.org/10.1177/000494411105500206

Burroughs, B. (2017). YouTube Kids: The App Economy and Mobile Parenting. Social Media+Society. https://doi.org/10.1177/2056305117707189

Buzzi, M. (2012). What Are Your Children Watching on YouTube? In Cipolla, F., Ficarra F., Veltman, K., Verber, D., \& Kammüller, F. (Eds.), Advances in New Technologies, Interactive Interfaces and Communicability, ADNTIIC 2011, 7547. Berlin: Springer.

Cavanaugh, C., Gillan, K. J, Kromrey, J., Hess, M., \& Blomeyer, R. (2004). The effects of distance education on $\mathrm{K}-12$ student outcomes: A meta-analysis, Naperville: Learning Point Associates.

Childwise. (2012). The Monitor Pre-school Report 2012: Key behaviour patterns among 0 to 4 year olds. Norwich: Childwise Research.

Edwards, S. (2013). Digital play in the early years: a contextual response to the problem of integrating technologies and play-based pedagogies in the early childhood. European Early Childhood Education Research Journal, 21(2), 199-212. https://doi.org/10.1080/1350293X.2013.789190

Gimbert, B., \& Cristol, D. (2004). Teaching curriculum with technology: Enhancing children's technological competence during early childhood. Early Childhood Education Journal, 31(3). https://doi.org/10.1023/B:ECEJ.0000012315.64687.ee

Grimes, S., \& Fields, D. (2012). Kids Online: A new research agenda for understanding social networking forums. New York: The Joan Ganz Cooney Centre.

Hiniker, A., Lee, B., Sobel, K., \& Choe, E. K. (2017). Plan \& Play: Supporting Intentional Media Use in Early Childhood. Proceedings of the 2017 Conference on Interaction Design and Children. Stanford: Association for Computing Machinery. https://doi.org/10.1145/3078072.3079752

Hipp, D., Gerhardstein, P., Zimmermann, L., Moser, A., Taylor, G., \& Barr, R. (2017). The dimensional divide: Learning from TV and touchscreens during early childhood. In R. 
Barr \& D. N. Linebarger (Eds.), Media exposure during infancy and early childhood: The effects of content and context on learning and development. Springer International Publishing. https://doi.org/10.1007/978-3-319-45102-2_3

Holloway, D., Green, L., \& Livingstone, S. (2013). Zero to eight. Young children and their internet use. London: EU Kids Online.

Livingstone, S., \& Haddon, L. (2008). Risky experiences for children online: Charting European research on children and the Internet. Children \& Society, 22(4), 314-323. https://doi.org/10.1111/j.1099-0860.2008.00157.x

Schofield Clark, L. (2011). Parental Mediation Theory for the Digital Age. Communication Theory, 21(4), 323-343, https://doi.org/10.1111/j.1468-2885.2011.01391.x

Marsh (2010). Young children's play in online virtual worlds. Journal of Early Childhood Research, 8(1), 23-39. https://doi.org/10.1177/1476718X09345406

Palaiologou, I. (2014). Children under five and digital technologies: implications for early years pedagogy. European Early Childhood Education Research Journal, 24(1), 1-20. https://dpi.org/ 10.1080/1350293X.2014.929876

Paparella, N. (2000). L'esperienza del bambino: ambienti, relazioni, artifici. In Cattanei G. (Eds.), Il bambino tra reale e virtuale. Brescia: La Scuola.

Paparella, N. (2012). L'agire didattico. Napoli: Guida.

Rek, M., \& Kovacic, A. (2019). Media and Preschool Children: The Role of Parents as Role Models and Educators. Medijske Studije, 9(18), 27-43. https://doi.org/10.20901/ms.9.18.2

Scott, F., \& Marsh, J. (2018). Digital Literacies in Early Childhood Digital literacies in early childhood. Oxford: Oxford Research Encyclopedia of Education. https://doi.org/10.1093/acrefore/9780190264093.013.97

Simone, M. G. (2008). Infanzia e gioco digitale. Problemi e prospettive. Studi e Ricerche, 15.

Stella, S., Riva, C., Scarcelli, C. M., \& Drusian, M (2014). Sociologia dei New Media. Torino: Utet.

Suoninen, A. (2014). Children's Media Barometer 2013. Media uses of 0-8 year-old Children and Changes in Media Uses Since 2010. Helsinki: Finnish Society on Media Education.

Tisseron, S. (2016). 3-6-9-12, Diventare grandi all'epoca degli schermi digitali. Brescia: La Scuola. 


\section{Copyright Disclaimer}

Copyright for this article is retained by the author(s), with first publication rights granted to the journal.

This is an open-access article distributed under the terms and conditions of the Creative Commons Attribution license (http://creativecommons.org/licenses/by/3.0/). 